Tropical Journal of Pharmaceutical Research June 2021; 20 (6): 1279-1284

ISSN: $1596-5996$ (print); 1596-9827 (electronic)

(C) Pharmacotherapy Group, Faculty of Pharmacy, University of Benin, Benin City, 300001 Nigeria.

Original Research Article

http://dx.doi.org/10.4314/tjpr.v20i6.26

\title{
Clinical efficacy of a combination of zoledronic acid and percutaneous vertebroplasty in spinal metastases and its influence on serum levels of bone loss markers
}

\author{
Shaokun Yang*, Bingguang Zuo, Guangning Ding \\ Cangzhou People's Hospital, Cangzhou, China \\ *For correspondence: Email: chongwcjaof46345@163.com \\ Sent for review: 25 February 2021 \\ Revised accepted: 24 May 2021
}

\begin{abstract}
Purpose: To investigate the clinical efficacy of zoledronic acid plus percutaneous vertebroplasty in spinal metastasis, and its effect on serum levels of bone loss markers.

Methods: Sixty-two patients with spinal metastases were randomly divided into study group $(n=31)$ and control group $(n=31)$. The control group underwent percutaneous vertebroplasty, while study group received zoledronic acid plus. Analgesic effect, Japanese Orthopedic Association (JOA) score, improvement in movement ability, quality of life, carboxy-terminal cross-linked peptide of type I collagen (ICTP), procollagen type I N-terminal amino peptide (PINP), and bone-specific alkaline phosphatase $(B A L P)$ levels were compared between the two groups.

Results: The study group presented a higher degree of analgesic effectiveness and better performance than the control group $(p<0.05)$. After treatment, the Kamofsky function scores were increased in both groups, but it was higher in the study group $(p<0.05)$. After treatment, the JOA score of the study group was higher than the control group $(p<0.05)$. The post-treatment levels of ICTP, PINP and BALP decreased in both groups, but was markedly lower in the study group $(p<0.05)$.

Conclusion: A combination of percutaneous vertebroplasty and zoledronic acid is effective for the treatment of spinal metastasis. It enhances mobility, improves quality of life, reduces serum levels of bone loss markers, and produces good analgesic effect.
\end{abstract}

Keywords: Percutaneous vertebroplasty, Zoledronic acid, Spinal metastasis, Pain, Quality of life

\begin{abstract}
This is an Open Access article that uses a fund-ing model which does not charge readers or their institutions for access and distributed under the terms of the Creative Commons Attribution License (http://creativecommons.org/licenses/by/4.0) and the Budapest Open Access Initiative (http://www.budapestopenaccessinitiative.org/read), which permit unrestricted use, distribution, and reproduction in any medium, provided the original work is properly credited.

Tropical Journal of Pharmaceutical Research is indexed by Science Citation Index (SciSearch), Scopus, International Pharmaceutical Abstract, Chemical Abstracts, Embase, Index Copernicus, EBSCO, African Index Medicus, JournalSeek, Journal Citation Reports/Science Edition, Directory of Open Access Journals (DOAJ), African Journal Online, Bioline International, Open-J-Gate and Pharmacy Abstracts
\end{abstract}

\section{INTRODUCTION}

Spinal metastasis, one of the most common bone metastases in orthopedic clinics, affects the vertebral body, resulting in pathological fractures, bone pain, spinal cord compression and hypercalcemia. It affects not only the quality of life of patients, but also their survival, especially in severe cases [1]. Spinal metastasis is usually aggressive, a feature which makes it difficult to completely remove through surgical treatment. Therefore, primary cancer and metastasis are usually treated with chemotherapy, radiotherapy and drugs so as to preserve nerve function, relieve pain, and stabilize or correct the shape of the spine [2]. Vertebroplasty significantly reduces vertebral metastasis-induced pain, enhances the stability of the spine and strengthens the 
vertebral body, and it is safe, simple and free from systemic adverse reactions [3]. Zoledronic significantly inhibits bone resorption caused by increased osteoclast activity acid by specifically acting on bone diphosphate compounds. Moreover, zoledronic acid selectively acts on bones and shows a high affinity for bone mineralization, making it the new standard treatment for cancer bone metastasis [4]. The aim of this study was to investigate the clinical efficacy of combination of zoledronic acid and percutaneous vertebroplasty in the treatment of spinal metastases, and its effect on serum levels of bone loss markers.

\section{METHODS}

\section{Patients and procedures}

This study enrolled 62 patients with spinal metastases in our hospital from January 2018 to January 2020 and randomly divided them into study group and control group, 31 cases in each group. This study was approved by Medical Science Research Ethics Committee of Cangzhou People's Hospital (approval no. 2017 (135)-152) and international guidelines for human studies were followed [5].

\section{Inclusion criteria}

The included patients were those who were diagnosed with bone metastasis through MRI or CT, X-ray and ECT, and patients who suffered from bone pain in line with the indications for vertebroplasty (in malignant spinal tumors, osteolytic bone metastases of spine and myeloma are usually painful, with multiple lesion foci, and it may be difficult for some patients in poor conditions to undergo surgery). One or two weeks of radiotherapy relieves pain in patients. Usually, if vertebroplasty is carried out, it immediately relieves the pain and increases the strength of the spine. Most spinal hemangiomas cause no symptoms at all. Thus, the occurrence of pain was an indication for the need for vertebroplasty. Patients signed a consent letter.

\section{Exclusion criteria}

Patients who had abnormal liver and kidney functions, patients who could not tolerate the treatments, and those whose previous endocrine therapy or chemotherapy was stopped for less than one month, were not enrolled in the study.

\section{Surgical procedures}

Patients in the control group underwent vertebroplasty. Before treatment, the patients were subjected to CT examination to measure the distance and angle between the skin and the lesion. Then, a surgery path was selected by avoiding important tissues and structures. All patients were in a lateral position under general anesthesia, and were operated on according to the surgical plan. After the patient was fixed with pedicle screws, the vertebral arch and small joints behind the diseased vertebrae were removed, and the visible tumor was scraped to a great extent, followed by insertion of the needle through the approach. When the needle point reached the target, a mixture of acrylic resin monomer and methacrylic resin polymer (in a ratio of $4: 1$ ) was injected into the diseased vertebral part. The study group was intravenously injected with zoledronic acid (Chia Tai Tianqing Pharmaceutical Group Co. Ltd., batch no. Zhunzi H20113138), $5 \mathrm{mg}$ at a time, once every 28 days, and a total of 4 injections.

\section{Clinical indices of treatment outcomes}

The were 4 categories of analgesic effect viz: CR, PR, MR and NR [5]. Analgesic effect was classified as $C R$ if patients had no pain at all, while PR was for significantly reduced pain, relative to pain before treatment, such that the patients lived normal lives, and their sleep was not generally affected by pain. Analgesic effect in MR grade was for patients whose pain was slightly relieved, relative to the situation before treatment, but their sleep was still disturbed. If there was no pain relief, the analgesic effect was classified as NR.

Improvement in movement was classified as significantly effective if movement ability was improved by $\geq$ two levels, compared to movement ability before treatment; effective if movement ability was improved by one level, relative to movement ability before treatment; or ineffective if there was no improvement or if there was a decrease in movement ability, when compared with movement ability before treatment [6]. The Kamofsky function scale was employed to assess the quality of life before and after treatment.

Lumbar vertebrae function was measured using the Japanese Orthopedic Association (JOA) scale [7]. In this scale, the full score for subjective symptoms was 9 points. These points covered low back pain, leg pain or numb pain, with scores ranging from 0 to 3 points. The full score for clinical signs was 6 points. These covered straight leg elevation test, sensory disorders and dyskinesia, and the scores ranged from 0 to 2 points, with muscle strength scoring from 0 to 3 points. The differences between the 
two groups before and after treatment were compared.

The levels of ICTP, PINP, and BALP in the two groups were assayed with ELISA kits before and after treatment, and compared. These parameters were also determined one week after treatment.

\section{Statistical analysis}

Measurement data are expressed as mean \pm standard error of the mean (S.E.M.), and were compared using independent paired $t$-test. Count data are expressed as numbers and percentages [n (\%)], and were compared using $\mathrm{x} 2$ test. All statistical analyses were done with SPSS23.0 statistical software. Values of $p<0.05$ were taken as indicative of statistically significant differences.

\section{RESULTS}

\section{Comparison of the general data}

In the study group, there were 31 patients comprising 18 males and 13 females, and their ages ranged from 35 to 80 years (mean age $=$ $50.03 \pm 6.43$ years). The 31 patients in the control group consisted of 17 males and 14 females, and their ages ranged from 34 to 81 years, with mean age of $49.58 \pm 4.44$ years. The baseline data of the two groups were comparable $(p>0.05)$. These baseline data are shown in Table 1.

Table 1: Comparative demographic profile $(n=31)$

\begin{tabular}{lcc}
\hline Group & $\begin{array}{c}\text { Gender } \\
\text { (Male/Female) }\end{array}$ & Age (years) \\
\hline Study & $18 / 13$ & $50.03 \pm 6.43$ \\
Control & $17 / 14$ & $49.58 \pm 4.44$ \\
$X^{2} / \mathrm{t}$ & 0.066 & 0.321 \\
$P$-value & 0.798 & 0.749 \\
\hline
\end{tabular}

\section{Effectiveness of pain relief}

The effectiveness of pain relief in the study group $(80.64 \%)$ was significantly higher than that in control group (41.94\%; $p<0.05)$. As shown in Table 2.
Table 2: Comparison of the effective rate $(n=31)$

\begin{tabular}{lccccc}
\hline Group & CR & PR & MR & NR & Total effective rate \\
\hline Study & 5 & 11 & 9 & 6 & $25(80.64)$ \\
Control & 2 & 6 & 5 & 18 & $13(41.94)$ \\
$X^{2}$ & & & & & 9.789 \\
$P$-value & & & & & 0.002 \\
\hline
\end{tabular}

\section{Movement ability (mobility)}

The movement improvement in the study group was $87.10 \%$, relative to $64.52 \%$ in the control group $(p<0.05)$, as shown in Table 3 .

\section{Kamofsky function scores}

After treatment, there were marked increases in the Kamofsky function scores of the two groups $(p<0.05)$. However, the study group had higher Kamofsky function score than the control group $(p<0.05)$. As shown in Figure 1.

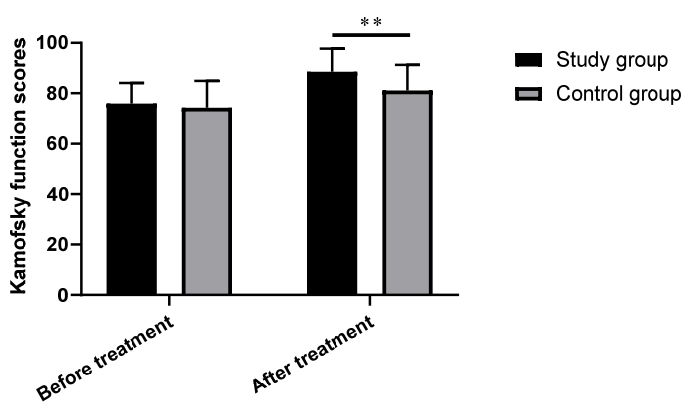

Figure 1: Comparison of Kamofsky function scores. ${ }^{* *} P<0.01$

\section{JOA scores}

There were increases in the JOA scores of the two groups after treatment $(p<0.05)$. However, JOA score was higher in the study group than in the control group $(p<0.05)$. As shown in Figure 2.

\section{Serum levels of bone loss markers}

The serum levels of bone loss markers in the two groups were decreased after treatment $(p<$ $0.05)$. However, there were higher decreases in bone loss markers in study group than in the control group $(p<0.05)$. As shown in Table 4.

Table 3: Comparison of movement improvement $(n=31)$

\begin{tabular}{lcccc}
\hline Group & Significant Effective & Effective & Ineffective & Total effectiveness \\
\hline Study & 16 & 11 & 4 & $27(87.10)$ \\
Control & 12 & 8 & 11 & $20(64.52)$ \\
$X^{2}$ & & & & 4.309 \\
$P$-value & & & & 0.038 \\
\hline
\end{tabular}


Table 4: Comparison of serum levels of bone loss markers (mean $\pm S D, n=31$ )

\begin{tabular}{ccccccc}
\hline & \multicolumn{2}{c}{ ICTP $(\boldsymbol{\mu g} / \mathbf{L})$} & \multicolumn{2}{c}{ PINP $(\mathbf{n g} / \mathbf{m l})$} & \multicolumn{1}{c}{ BALP(U/L) } \\
\cline { 2 - 7 } Group & $\begin{array}{c}\text { Before } \\
\text { treatment }\end{array}$ & $\begin{array}{c}\text { After } \\
\text { treatment }\end{array}$ & Before treatment & After treatment & Before treatment & After treatment \\
\hline Study & $8.70 \pm 0.27$ & $5.35 \pm 0.14$ & $132.55 \pm 15.98$ & $83.86 \pm 14.89$ & $653.58 \pm 27.94$ & $493.45 \pm 27.60$ \\
Control & $8.78 \pm 0.24$ & $6.55 \pm 0.34$ & $132.12 \pm 22.18$ & $100.17 \pm 23.35$ & $668.26 \pm 35.99$ & $585.65 \pm 44.75$ \\
$t$ & 1.131 & 18.169 & 0.087 & 3.279 & 1.793 & 9.763 \\
$P$-value & 0.263 & $<0.001$ & 0.931 & 0.002 & 0.078 & $<0.001$ \\
\hline
\end{tabular}

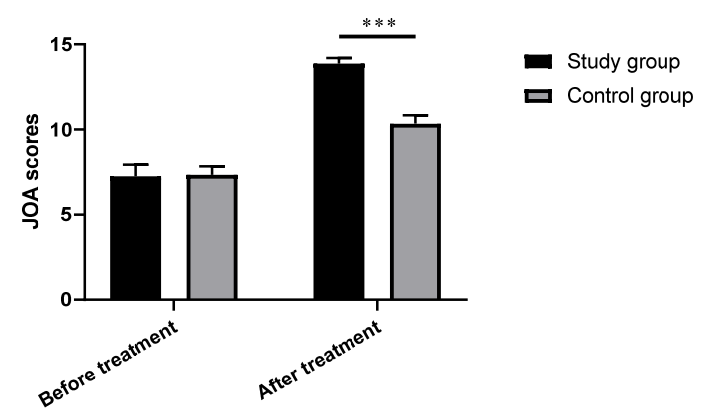

Figure 2: Comparison of JOS scores. ${ }^{* *} P<0.001$

\section{DISCUSSION}

Bone metastasis is a common complication in advanced cancers. Indeed, 30-85 \% of cancer patients suffer from bone metastasis, mostly at the spine. A study has revealed that $5-10 \%$ of cancer patients have spinal metastasis which is seen in $90 \%$ of patients who die of cancers [8]. Patients with spinal metastasis usually suffer from bone pain, pathological fractures, compressive myelopathy and paralysis which severely influence their quality of life [9]. It is generally known that tumors move to bone tissue, resulting in increased osteoclast activity and osteolysis. Thereafter, the tumor cells infiltrate into the periosteum and surrounding soft tissues, leading to pain. In addition, tumor cells or local inflammatory cells secrete inflammatory mediators such as PG, IL-1 and TNF which cause pain in patients through stimulation of nerve endings. Patients with spinal metastasis experience severe and long-lasting pain which cannot be relieved by analgesics, and some patients may undergo pathological fractures or compressive myelopathy, leading to paraplegia [10-12]. Therefore, there is need for these patients to receive effective treatment.

At present, it is difficult to radically remove spinal metastases. Consequently, treatment methods are focused on how to relieve the symptoms and improve the quality of life of the patients. These treatments involve radiotherapy, chemotherapy, surgery, radionuclide therapy and use of bisphosphonates. It has been reported that comprehensive treatment measures achieve the best efficacies [13]. Vertebroplasty enhances the physical stability of the infiltrated vertebra. The procedure is associated with decreased tissue damage and minimal invasiveness. It eliminates the stimulation of painful nerve endings due to friction and compression, thereby improving the quality of life of patients [14]. However, vertebroplasty is associated with complications like puncture injury, bone cement leakage and pulmonary embolism. Zoledronic acid, a new generation bisphosphonate drug with the strongest pharmacological activity so far, effectively inhibits the activity of osteoclasts. It directly blocks bone destruction by osteoclasts, inhibits the biosynthetic pathways of formaldehyde and valeric acid, and inhibits the activity of farnesyl pyrophosphate synthase, resulting in the inhibition of osteoclasts activity and induction of osteoclast apoptosis. Moreover, it inhibits the transformation of precursor cells into mature osteoclasts, and also blocks the synthesis of osteoclasts and the release of prostaglandins [15]. Zoledronic acid is used for relief of bone pain and pain from pathological fractures. It improves the quality of life of patients, and is beneficial for patients in whom other bisphosphonate drugs fail to achieve efficacy. Due to its high efficacy and short infusion time, zoledronic acid has become the new treatment option for bone metastases [16].

The results of this study showed that the combination of vertebroplasty with zoledronic acid relieved pain in patients with spinal metastases and enhanced movement ability. Thus, the combination treatment produced a great analgesic effect in patients with spinal metastases, consistent with the results of similar studies [17]. When bone cement is injected into vertebra, it mitigates compression fracture in patients with spinal metastases, enhances support of the bone trabecula, and stabilizes the vertebra. In patients with vertebral fracture, it rebuilds the stability of the spine, markedly improves its kyphosis and restores the height of the affected vertebra. In addition, the heat and cytotoxicity generated during bone cement polymerization not only promote necrosis of surrounding tumor cells, but also destroys nearby nerve endings, thereby effectively reducing pain. Zoledronic acid effectively inhibits osteoclast 
activity and promotes apoptosis of osteoclasts, inhibits osteoclast synthesis and suppresses the release of interleukins and prostaglandins. It also binds to bone and prevents osteoclasts from dissolving cartilage and mineralized bone, and blocks the release of bone calcium due to a variety of stimulating factors from tumors [18,19]. This study has revealed that zoledronic acid reduced complications of cancer bone metastasis. Patients with spinal metastasis were treated with zoledronic acid, and the serum levels of new bone loss markers (ICTP, PINP and BALP) were determined. It was found that the serum levels of bone loss markers in the two groups were decreased after treatment, but more marked decrease was seen in the study group. The decreases in serum levels of bone loss markers may be due to the fact that zoledronic acid up-regulated osteoprotegerin (OPG) and down-regulated RANKL. In addition, the cannabinoid receptor type2 (CB2) and inverse agonist AM630 mitigated the pain caused by zoledronic acid in patients with spinal metastases, indicating that zoledronic acid reduced the pain and bone destruction through CB2 mediation [20].

\section{Limitations of the study}

First of all, the statistic results might be biased due to the small sample size plus the nonuniform baseline standards when selecting the samples. Second, the biological and histological characteristics of various primary malignant tumors and the degree of spinal disease at the time of treatment is inconsistent, which can cause statistical errors. The conclusions drawn in this study are only preliminary, and no further stratification and multivariate analysis of the cases was conducted. Further studies with a larger sample size, longer follow-up and more rigorous experimental design are needed to clarify the research conclusions.

\section{CONCLUSION}

The combination of zoledronic acid and percutaneous vertebroplasty is an effective treatment for spinal metastasis. It produces good analgesic effect, improves movement ability and quality of life of patients, and reduces serum levels of bone loss markers.

\section{DECLARATIONS}

\section{Conflict of interest}

No conflict of interest is associated with this work.

\section{Contribution of authors}

We declare that this work was done by the authors named in this article and all liabilities pertaining to claims relating to the content of this article will be borne by the authors.

\section{Open Access}

This is an Open Access article that uses a funding model which does not charge readers or their institutions for access and distributed under the terms of the Creative Commons Attribution License (http://creativecommons.org/licenses/by/ 4.0) and the Budapest Open Access Initiative (http://www.budapestopenaccessinitiative.org/rea d), which permit unrestricted use, distribution, and reproduction in any medium, provided the original work is properly credited.

\section{REFERENCES}

1. Juárez P, Fournier PGJ, Mohammad KS, McKenna RC, Davis HW, Peng $X H$, Niewolna M, Mauviel A, Chirgwin JM, Guise TA. Halofuginone inhibits TGF- $\beta / B M P$ signaling and in combination with zoledronic acid enhances inhibition of breast cancer bone metastasis. Oncotarget. 2017; 8(49): 86447-86462.

2. Tai $N$, Inoue $D$. Bone and calcium metabolism associated with malignancy. Malignancy-associated hypercalcemia. Clin Calcium. 2018; 28(11): 1503-1508.

3. Harrer DC, Simon B, Fujii SI, Shimizu K, Uslu U, Schuler G, Gerer KF, Hoyer S, Dörrie J, Schaft N. RNAtransfection of $\gamma / \delta T$ cells with a chimeric antigen receptor or an $\alpha / \beta$ T-cell receptor: a safer alternative to genetically engineered $\alpha / \beta \quad T$ cells for the immunotherapy of melanoma. BMC Cancer 2017; 17(1): 551.

4. Vignani F, Bertaglia V, Buttigliero C, Tucci M, Scagliotti GV, Di Maio M. Skeletal metastases and impact of anticancer and bone-targeted agents in patients with castration-resistant prostate cancer. Cancer Treat Rev 2016; 44: 61-73.

5. Department of Health, Education, and Welfare; National Commission for the Protection of Human Subjects of Biomedical and Behavioral Research. The Belmont Report. Ethical principles and guidelines for the protection of human subjects of research. J Am Coll Dent 2014; 81(3): 4-13.

6. Jakob T, Tesfamariam YM, Macherey S, Kuhr K, Adams A, Monsef I, Heidenreich A, Skoetz N. Bisphosphonates or RANK-ligand-inhibitors for men with prostate cancer and bone metastases: a network meta-analysis. Cochrane Database Syst Rev 2020; 12(12): CD013020.

7. Lüftner D, Niepel D, Steger GG. Therapeutic approaches for protecting bone health in patients with breast cancer. Breast 2018; 37: 28-35. 
8. Zhang $H R$, Xu MY, Yang XG, Qiao RQ, Li JK, Hu YC. Percutaneous vertebral augmentation procedures in the management of spinal metastases. Cancer Lett 2020; 475: 136-142.

9. Kam NM, Maingard J, Kok HK, Ranatunga $D$, Brooks $D$, Torreggiani WC, Munk PL, Lee MJ, Chandra RV, Asadi H. Combined Vertebral Augmentation and Radiofrequency Ablation in the Management of Spinal Metastases: an Update. Curr Treat Options Oncol 2017; 18(12): 74.

10. Barzilai O, Fisher CG, Bilsky MH. State of the Art Treatment of Spinal Metastatic Disease. Neurosurgery. 2018; 82(6): 757-769.

11. Health Quality Ontario. Vertebral Augmentation Involving Vertebroplasty or Kyphoplasty for Cancer-Related Vertebral Compression Fractures: A Systematic Review. Ont Health Technol Assess Ser 2016; 16(11): 1-202.

12. Abbouchie H, Chao M, Tacey M, Lim Joon D, Ho H, Guerrieri $M, N g$, Foroudi $F$. Vertebral fractures following stereotactic body radiotherapy for spine metastases. J Med Imaging Radiat Oncol 2020; 64(2): 293-302.
13. Leone A, Cianfoni A, Zecchi V, Cortese MC, Rumi N, Colosimo C. Instability and impending instability in patients with vertebral metastatic disease. Skeletal Radiol 2019; 48(2): 195-207.

14. Myrehaug S, Soliman H, Tseng C, Heyn C, Sahgal A. Re-irradiation of Vertebral Body Metastases: Treatment in the Radiosurgery Era. Clin Oncol 2018; 30(2): 85-92.

15. Tomasian A, Jennings JW. Vertebral Metastases: Minimally Invasive Percutaneous Thermal Ablation. Tech Vasc Interv Radiol 2020; 23(4): 100699.

16. Zeng KL, Tseng CL, Soliman $H$, Weiss $Y$, Sahgal A, Myrehaug S. Stereotactic Body Radiotherapy (SBRT) for Oligometastatic Spine Metastases: An Overview. Front Oncol 2019; 9: 337.

17. Elmaci I, Altinoz MA, Ozlu BEK, Sari R, Er O, Danyeli AE, Karaarslan E. Benign leiomyoma with multiple metastases to vertebrae and calvarium: An index case with comprehensive review of endocrine targets. Neurosurg Rev 2021; 44(1): 289-300.

18. Liu T, Wang S, Liu H, Meng B, Zhou F, He F, Shi X, Yang $H$. Detection of vertebral metastases: a meta-analysis comparing MRI, CT, PET, BS and BS with SPECT. J Cancer Res Clin Oncol 2017; 143(3): 457-465. 